\title{
Cadmium induced changes in subcellular glutathione contents within glandular trichomes of Cucurbita pepo $\mathrm{L}$.
}

\author{
Dagmar Kolb • Maria Müller • Günther Zellnig • \\ Bernd Zechmann
}

Received: 28 January 2009 / Accepted: 15 April 2009/Published online: 8 May 2009

(C) The Author(s) 2009. This article is published with open access at Springerlink.com

\begin{abstract}
Plants cope with cadmium (Cd) stress by complexation with phytochelatins $(\mathrm{Pc})$, metallothioneins and glutathione and sequestration within vacuoles. Especially glutathione was found to play a major role in $\mathrm{Cd}$ detoxification as $\mathrm{Cd}$ shows a high binding affinity towards thiols and as glutathione is a precursor for Pc synthesis. In the present study, we have used an immunohistochemical approach combined with computer-supported transmission electron microscopy in order to measure changes in the subcellular distribution of glutathione during Cd-stress in mesophyll cells and cells of different glandular trichomes (long and short stalked) of Cucurbita pepo L. subsp. pepo var. styriaca GREB. Even though no ultrastructural alterations were observed in leaf and glandular trichome cells after the treatment of plants with $50 \mu \mathrm{M}$ cadmium chloride $\left(\mathrm{CdCl}_{2}\right)$ for $48 \mathrm{~h}$, all cells showed a large decrease in glutathione contents. The strongest decrease was found in nuclei and the cytosol (up to $76 \%$ ) in glandular trichomes which are considered as a major side of $\mathrm{Cd}$ accumulation in leaves. The ratio of glutathione between the cytosol and nuclei and the other cell compartments was strongly decreased only in glandular trichomes (more than 50\%) indicating that glutathione in these two cell compartments is especially important for the detoxification of $\mathrm{Cd}$ in glandular trichomes. Additionally, these data indicate that large amounts of $\mathrm{Cd}$ are withdrawn from nuclei during $\mathrm{Cd}$ exposure. The present study gives a detailed insight into the
\end{abstract}

Dedicated to Professor Cornelius Lütz on the occasion of his 65th birthday

Dagmar Kolb and Maria Müller have contributed equally to this article.

D. Kolb $\cdot$ M. Müller $(\bowtie) \cdot$ G. Zellnig $\cdot$ B. Zechmann

Institute of Plant Sciences, University of Graz,

Schubertstrasse 51,

8010 Graz, Austria

e-mail: maria.mueller@uni-graz.at compartment-specific importance of glutathione during $\mathrm{Cd}$ exposure in mesophyll cells and glandular trichomes of $C$. pepo L. plants.

Keywords Cadmium · Cucurbita pepo .

Electron microscopy $\cdot$ Glutathione $\cdot$ Immunohistochemistry
Abbreviations
BSA bovine serum albumin
$\mathrm{Cd}$ cadmium
PC phytochelatins
PBS phosphate-buffered saline
RT room temperature

\section{Introduction}

Soil contamination with heavy metals can be a significant problem for plant growth and development as high concentrations of heavy metals tend to accumulate within plant organs and negatively interfere with essential physiological processes. One of the most commonly found heavy metal in soil is cadmium (Cd). It can be naturally found in low concentrations in the environment and tends to accumulate to high and toxic concentrations in connection with mining, zinc smelting, burning of fuel, phosphate fertilization and the excessive use of sewage sludge in agriculture (Toppi and Gabbrielli 1999; DalCorso et al. 2008). Cd is a highly reactive heavy metal and shows a high affinity towards functional groups of biomolecules (i.e., amino, carboxy, phosphate, and thiol groups; MendozaCózatl et al. 2005). Therefore, it interacts with various physiological processes that are essential for plant metabolism such as photosynthesis, respiration, or transpiration (DalCorso et al. 2008; Ekmekci et al. 2008; He et al. 2008). 
Indirectly, high concentrations of $\mathrm{Cd}$ can lead to oxidative stress resulting in an increase in anti-oxidative defense enzymes (Toppi and Gabbrielli 1999; Hegedüs et al. 2001; DalCorso et al. 2008; Ekmekci et al. 2008; Paradiso et al. 2008; $\mathrm{Xu}$ et al. 2008). Lipid peroxidation within plants leading to alterations in the functionality of membranes and the breakdown of chlorophyll is also a commonly observed effect of Cd exposure (Schützendübel et al. 2001; RomeroPuertas et al. 2002; Singh et al. 2006; DalCorso et al. 2008: Paradiso et al. 2008; Xu et al. 2008). Visible symptoms (e.g., leaf roll, growth inhibition, chlorosis, root damage) are therefore a commonly observed consequence after the exposure of plants to toxic concentrations of $\mathrm{Cd}$.

Even though $\mathrm{Cd}$ is not essential for plant metabolism it is readily taken up by roots and transported through xylem and phloem to the different organs (DalCorso et al. 2008; Mendoza-Cózatl et al. 2008). Cd accumulation in different organs and tissues varies greatly throughout different plant species. As plants are not able to metabolize or eliminate $\mathrm{Cd}$ it is generally detoxified by complexation with phytochelatins (PCs), metallothioneins, and also glutathione and subsequently by sequestration within vacuoles (Toppi and Gabbrielli 1999; Rauser 2001; DalCorso et al. 2008). The long-distance transport of $\mathrm{Cd}-\mathrm{Pc}$ and $\mathrm{Cd}$ glutathione complexes through xylem and phloem vessels also seems to play an important role in the detoxification of Cd (Mendoza-Cózatl et al. 2008). Glutathione fulfills various important roles in the detoxification of $\mathrm{Cd}$ and therefore changes in glutathione contents are commonly observed during the exposure of plants to high levels of $\mathrm{Cd}$ (Zawoznik et al. 2007; Ammar et al. 2008; DalCorso et al. 2008; Dučić et al. 2008; Nocito et al. 2008). Glutathione is not only responsible for the direct complexation of $\mathrm{Cd}$ and sequestration in vacuole but is also involved indirectly in the detoxification of $\mathrm{Cd}$ by acting as a substrate for PC synthesis and by detoxifying reactive oxygen species that are commonly produced during Cd exposure (Rauser 2001; Maksymiec and Krupa 2006; DalCorso et al. 2008). Additionally, glutathione protects proteins during $\mathrm{Cd}$ exposure by binding to their $\mathrm{SH}$ groups which would otherwise be a potential binding site for $\mathrm{Cd}$. The importance of glutathione in the detoxification of $\mathrm{Cd}$ is also supported by the Cd-sensitive Arabidopsis mutant cad 2-1 that shows only about $15-45 \%$ of glutathione, measured with biochemical methods, in comparison to the wildtype (Howden et al. 1995; Cobbett et al. 1998).

So far, very little is known about changes in the subcellular distribution of glutathione during $\mathrm{Cd}$ exposure in plants which would give valuable information about possible compartment-specific $\mathrm{Cd}$ detoxification pathways that include glutathione. Most data about changes in glutathione contents during $\mathrm{Cd}$ exposure have been collected in whole organs or within vascular bundle cells (Semane et al. 2007; Zawoznik et al. 2007; Ammar et al. 2008; DalCorso et al. 2008; Dučić et al. 2008; Nocito et al. 2008) and it remains unclear to which extend $\mathrm{Cd}$ exposure changes subcellular glutathione contents. Therefore the present study was aimed at investigating compartmentspecific changes in glutathione contents during $\mathrm{Cd}$ exposure in order to characterize the importance of glutathione in the compartment-specific protection against $\mathrm{Cd}$. In the present study these changes were not only measured in mesophyll cells of leaves but also in glandular trichomes which are known to accumulate and extrude large amounts of heavy metal (Choi et al. 2001; Ager et al. 2002, 2003; Isaure et al. 2006; Harada and Choi 2008) suggesting an important role of these epidermal structures in the detoxification of $\mathrm{Cd}$. As it is technically challenging to measure glutathione contents in glandular trichomes with biochemical methods, immunocytochemistry combined with computer-supported transmission electron microscopy (Zechmann et al. 2006, 2008) was used in order to characterize Cd-induced changes in compartment-specific glutathione distribution.

These studies were aimed to gain a deeper insight into Cd-induced impacts on the subcellular level of different cell types of Styrian oil pumpkin, especially in connection with changes in subcellular glutathione contents, since so far very little was known about possible compartment-specific $\mathrm{Cd}$ detoxification pathways including glutathione.

\section{Materials and methods}

\section{Plant material}

Seeds of Styrian oil pumpkin (Cucurbita pepo L. subsp. pepo var. styriaca GREB.) obtained from Saatzucht Gleisdorf (Plant Breeding Company Gleisdorf, Austria), were germinated on humid Perlite. Throughout the experiment plants were cultivated in climate chambers with a photoperiod of $12 \mathrm{~h}$ and a light intensity between 150 to $170 \mu \mathrm{mol} \mathrm{m}^{-2} \mathrm{~s}^{-1}$. Day and night temperatures were $22^{\circ} \mathrm{C}$ and $18^{\circ} \mathrm{C}$ respectively, the relative humidity was $70 \%$. Cd-treatment experiments were performed with two weeks old Styrian oil pumpkin seedlings by immersing the roots into a $50 \mu \mathrm{M} \mathrm{CdCl}_{2}$ solution (pH 5.8) for $48 \mathrm{~h}$. Control plants were kept in the same solution but without $\mathrm{CdCl}_{2}$. The solutions were renewed after $24 \mathrm{~h}$. Youngest fully developed leaves were harvested $48 \mathrm{~h}$ after $\mathrm{Cd}$ treatment and $2 \mathrm{~h}$ after the onset of light for ultrastructural and immunocytochemical investigations.

Transmission electron microscopy investigations

Small leaf samples (about $1.5 \mathrm{~mm}^{2}$ ) from at least three different plants were cut on a modeling wax plate either in a 
drop of (a) 3\% glutardialdehyde in $0.06 \mathrm{M}$ Sørensen phosphate buffer ( $\mathrm{pH}$ 7.2) for ultrastructural investigations or (b) in a drop of $2.5 \%$ paraformaldehyde $/ 0.5 \%$ glutardialdehyde in $0.06 \mathrm{M}$ Sørensen phosphate buffer ( $\mathrm{pH} 7.2$ ) for cytohistochemical analysis. Samples were then transferred into glass vials and fixed for $90 \mathrm{~min}$ at room temperature (RT) in the above-mentioned media.

For ultrastructural analysis, samples were then rinsed in buffer (four times, $15 \mathrm{~min}$ each) and post-fixed in $1 \%$ osmium tetroxide in $0.06 \mathrm{M}$ Sørensen phosphate buffer for $90 \mathrm{~min}$ at RT. The samples were then dehydrated in increasing concentrations of acetone $(50 \%, 70 \%, 90 \%$, and $100 \%$ ). Pure acetone was then exchanged by propylene oxide and specimen were gradually infiltrated with increasing concentrations of Agar 100 epoxy resin $(30 \%, 60 \%$, and $100 \%$ ) mixed with propylene oxide for a minimum of $3 \mathrm{~h}$ per step. Samples were finally embedded in pure, fresh Agar 100 epoxy resin (Agar Scientific Ltd, Stansted, UK) and polymerized at $60^{\circ} \mathrm{C}$ for $48 \mathrm{~h}$.

For cytohistochemical investigations samples were rinsed in buffer (four times, $15 \mathrm{~min}$ each) after fixation and then dehydrated in increasing concentrations of acetone $(50 \%, 70 \%$, and $90 \%)$ for two times, $10 \mathrm{~min}$ each. Subsequently, specimens were gradually infiltrated with increasing concentrations of LR-White resin $(30 \%, 60 \%$, and $100 \%$; London Resin Company Ltd., Berkshire, UK) mixed with acetone $(90 \%)$ for a minimum of $3 \mathrm{~h} / \mathrm{step}$. Samples were finally embedded in pure, fresh LR-White resin and polymerized at $50^{\circ} \mathrm{C}$ for $48 \mathrm{~h}$ in small plastic containers under anaerobic conditions. Ultrathin sections $(80 \mathrm{~nm})$ were cut with a Reichert Ultracut $\mathrm{S}$ ultramicrotome. For ultrastructural investigations sections were poststained for $5 \mathrm{~min}$ with lead citrate and for fifteen minutes with uranyl acetate at RT before they were observed with a Philips CM10 transmission electron microscope. For cytohistochemical investigations sections remained either unstained or were stained for $15 \mathrm{~s}$ with $2 \%$ uranyl acetate dissolved in aqua bidest at RT.

\section{Cytohistochemical investigations}

Immunogold-labeling of glutathione was done with ultrathin sections on nickel grids as described in Zechmann et al. 2006. Briefly, samples were blocked with $2 \%$ bovine serum albumin (BSA) in phosphate-buffered saline (PBS, $\mathrm{pH}$ 7.2) for $20 \mathrm{~min}$ at RT. The samples were then treated with the primary antibody (anti-glutathione rabbit polyclonal $\mathrm{IgG}$; Chemicon International, California) diluted 1:50 in PBS containing 1\% goat serum for $2 \mathrm{~h}$ at RT. After a short rinse in PBS (three times, $5 \mathrm{~min}$ ), the samples were incubated with a 10-nm gold-conjugated secondary antibody (goat anti rabbit IgG, British BioCell International, Cardiff, www.british-biocell.co.uk) diluted 1:50 in PBS for
90 min at RT. After a short wash in PBS (three times, $5 \mathrm{~min}$ ) and distilled water (two times, $5 \mathrm{~min}$ ), labeled grids were either immediately observed in a Philips CM10 transmission electron microscope or post-stained with uranyl acetate $(15 \mathrm{~s})$. Post-staining with uranyl acetate was applied to facilitate the distinction of different cell structures enabling a clearer identification of the investigated organelles.

The selectivity and proper affinity of the primary antibody against glutathione has been tested with competition assays in tissue sections using bona fide GSH and GSSG as the target and a range of displacers. No measurable glutardialdehyde-fixed tissue cross-reactivity against L-alanine, $\gamma$-aminobutyrate, 1-amino-4-guanidobutane (AGB), D/L-arganine, D/L-aspartate, L-citrulline, Lcysteine, D/L-glutamate, D/L-glutamine, glycine, L-lysine, L-ornithine, L-serine, taurine, L-threonine, L-tryptophan, Ltyrosine was detected. Additionally, the antibody did not bind to glutathionylated proteins on Western Blot experiments nor to glutathionylated proteins in sections fixed with formaldehyde (see technical note for glutathione antibody on the website of the manufacturer www.immunologics. com). Therefore, a reaction of the antibody with glutathionylated proteins bound by glutardialdehyde to the protein matrix of the tissue on ultrathin section seems very unlikely. The antibody does not discriminate between free reduced and oxidized glutathione (according to Signature Immunologics Inc.).

Several negative controls were made to confirm the specificity of the immunogold procedure. Negative controls were treated either with: (1) gold-conjugated secondary antibody (goat anti-rabbit $\operatorname{IgG}$ ) without prior incubation of the section with the primary antibody, (2) non specific secondary antibody (goat anti-mouse IgG), and (3) primary antibody pre-adsorbed with an excess of glutathione for $2 \mathrm{~h}$ at RT prior to labeling of the sections. For the latter antibody, a solution containing $10 \mathrm{mM}$ of glutathione was incubated with $0.5 \%$ glutardialdehyde for $1 \mathrm{~h}$. The excess of glutardialdehyde was then saturated by incubation for $30 \mathrm{~min}$ in a solution of $1 \%(w / v)$ BSA. The resulting solution was used to saturate the anti-glutathione antibodies for $2 \mathrm{~h}$ prior to its use in the immunogold-labeling procedure described above.

\section{Quantitative analysis of immunogold-labeling}

Micrographs of randomly photographed immunogold labeled sections of mesophyll cells and two different glandular trichome types (type I, the short-stalked trichome with four head cells; type II, the long-stalked trichome with two head cells, see Kolb and Müller 2004) were digitized and gold particles were counted automatically using the software package Optimas 6.5.1 (Media Cybernetics Inc., 
Bethesda, Maryland; www.mediacy.com) in different visually identified cell structures (mitochondria, plastids, nuclei, and the cytosol). Due to the low amount of gold particles found in the apoplast, vacuoles, endoplasmic reticulum (ER), and dictyosomes, no statistical evaluation of the gold particle density was made for these compartments. For statistical evaluation, at least three different leaf samples were examined. Between 20 and 60 sectioned cell structures of at least 15 different cells throughout the block were analyzed for gold particle density. The obtained data were statistically evaluated using Statistica (Stat-Soft, USA, 1994) and presented as the number of gold particles per $\mu \mathrm{m}^{2}$. Unspecific background labeling was determined on 30 different sections (outside the specimen) from five different samples and subtracted from the obtained values inside the sample. Unspecific background labeling was around 0.3 gold particles $/ \mu \mathrm{m}^{2}$. For all statistical analyses, the non-parametric Kruskal-Wallis test followed by a post- hoc comparison according to Conover was used (Bortz et al. 2000). $P<0.05$ was regarded significant.

\section{Results}

No visible ultrastructural modifications were observed in Cd-treated mesophyll cells and in the glandular trichome cells (head- and stalk cells), in comparison to the control plant material (data not shown). The cell structure of glandular trichome cells looked similar to what has been described by Kolb and Müller 2004. Highest levels of glutathione were always found in mitochondria. Immunogold-labeling of glutathione in mesophyll cells and glandular trichomes was similar as previously described for C. pepo leaf cells (Zechmann et al. 2006). Second-highest labeling density was always found in nuclei. In mesophyll cells, plastids contained the lowest amounts of gold particles (about 90\%
Fig. 1 Immunogold-labeling of glutathione. Transmission electron micrographs show gold particles bound to glutathione in mesophyll (a, b), long- (c, d) and short-stalked $(\mathbf{e}, \mathbf{f})$ glandular trichome cells from leaves of Cucurbita pepo (L.). Lower gold particle density can be found in cells of plants treated with $50 \mu \mathrm{m}$ cadmium $(\mathbf{b}, \mathbf{d}, \mathbf{f})$ in comparison to the control $(\mathbf{a}, \mathbf{c}$, e). $C W$ cell walls, $M$ mitochondria, $N$ nuclei, $P$ plastids, $S t$ starch, $V$ vacuoles. Sections were post-stained with uranyl acetate for $15 \mathrm{~s}$. Bars $1 \mu \mathrm{m}$
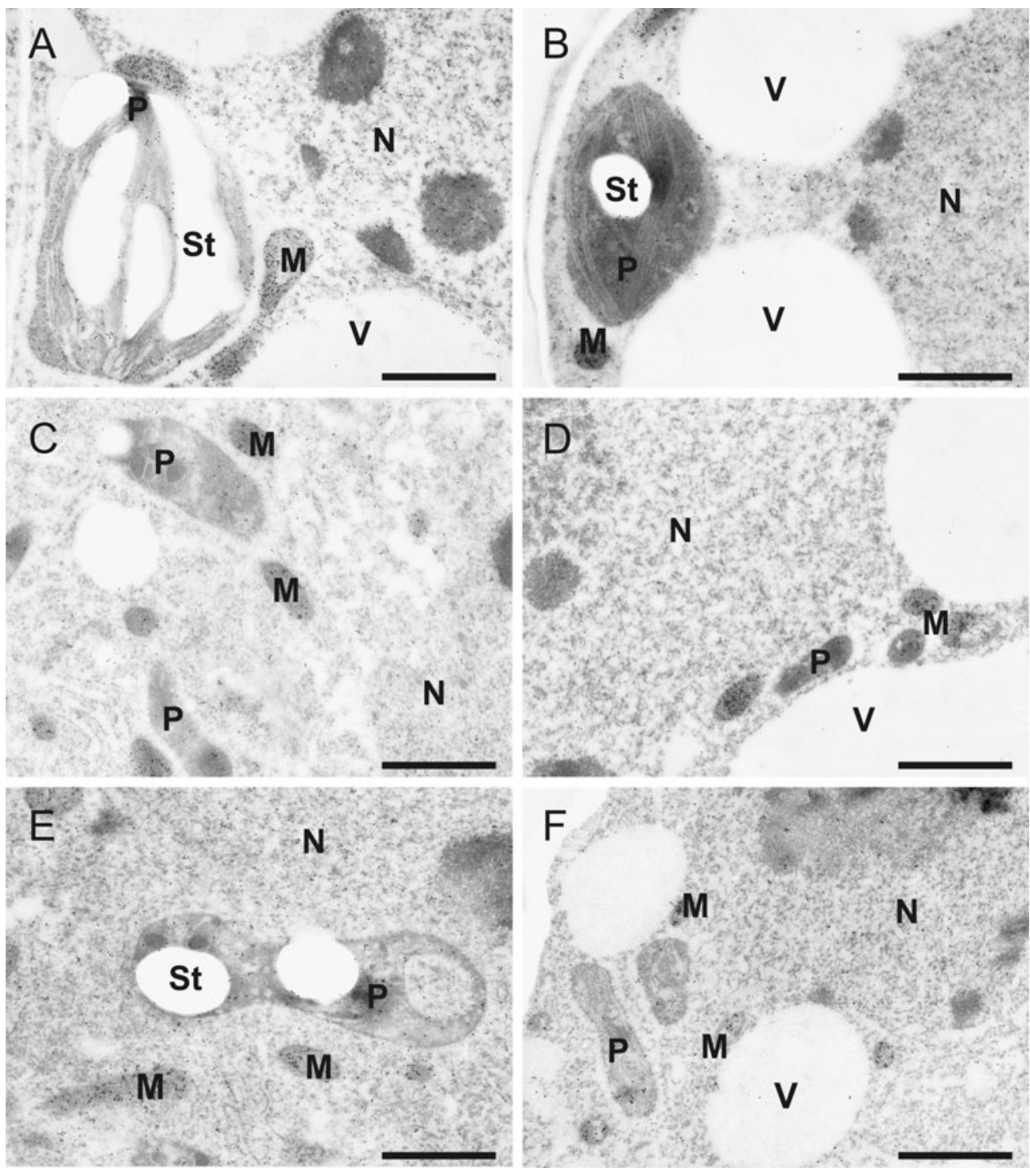
lower than in mitochondria) whereas in glandular trichomes, the cytosol showed the lowest amounts of gold labeling of glutathione (about 90\% lower than in mitochondria). Glutathione contents in mesophyll cells were similar to what was found in glandular trichome cells (Fig. 1 and Table 1). A significant difference in glutathione contents between different cells was found in nuclei of long-stalked glandular trichome cells, which contained about $37 \%$ and $18 \%$ more glutathione than the same organelle in mesophyll and shortstalked glandular trichome cells, respectively.

$\mathrm{Cd}$ treatment significantly reduced immunogold labeling of glutathione in all cell compartments of mesophyll cells and glandular trichomes (Fig. 1 and Table 1). In mesophyll cells, glutathione levels were decreased after $\mathrm{Cd}$ treatment of about $43 \%$ in plastids, $38 \%$ in the cytosol, $34 \%$ in mitochondria, and $30 \%$ in nuclei. In long- and short-stalked glandular trichome cells a much stronger decrease of glutathione was observed in nuclei $(76 \%$ and $70 \%)$ and in the cytosol (74\% and 76\%) in comparison to mesophyll cells whereas the decrease in glutathione contents was similar to mesophyll cells in plastids (33\% and $45 \%)$ and mitochondria (25\% and $27 \%$ ). Interestingly, the ratio of glutathione between organelles was strongly changed in glandular trichome cells but not in mesophyll cells (Table 2). In long- and short-stalked glandular trichomes the glutathione pool decreased in the cytosol from $7 \%$ to $2.8 \%$ and in nuclei from about $11-12 \%$ to about $5 \%$ of the total glutathione pool found in glandular trichomes. On the other side, the ratio of glutathione increased in mitochondria which contained between $72 \%$ and $74 \%$ of the total glutathione before $\mathrm{Cd}$ treatment and about $83.5 \%$ to $84.9 \%$ of the total glutathione after $\mathrm{Cd}$ treatment within long- and short-stalked glandular trichome cell. No significant change in glutathione pool was observed in plastids.

\section{Discussion}

Glutathione plays an important role in plants in the detoxification of Cd (Toppi and Gabbrielli 1999; DalCorso et al 2008). Nevertheless, it remained unclear to which extend $\mathrm{Cd}$ exposure alters the subcellular distribution of glutathione in plant leaf cells and especially in glandular trichome cells which are known to accumulate and even excrete large amounts of heavy metals (Choi et al. 2001; Ager et al. 2002, 2003; Isaure et al. 2006; Harada and Choi 2008). Generally, glutathione contents were found to be similar in mesophyll cells and glandular trichome cells of control plants indicating that there is no difference in the distribution and levels of subcellular glutathione contents between these cell types in non-stressed plants. Within these cells, glutathione contents were found to be similar to what has recently been reported for Arabidopsis, Beta

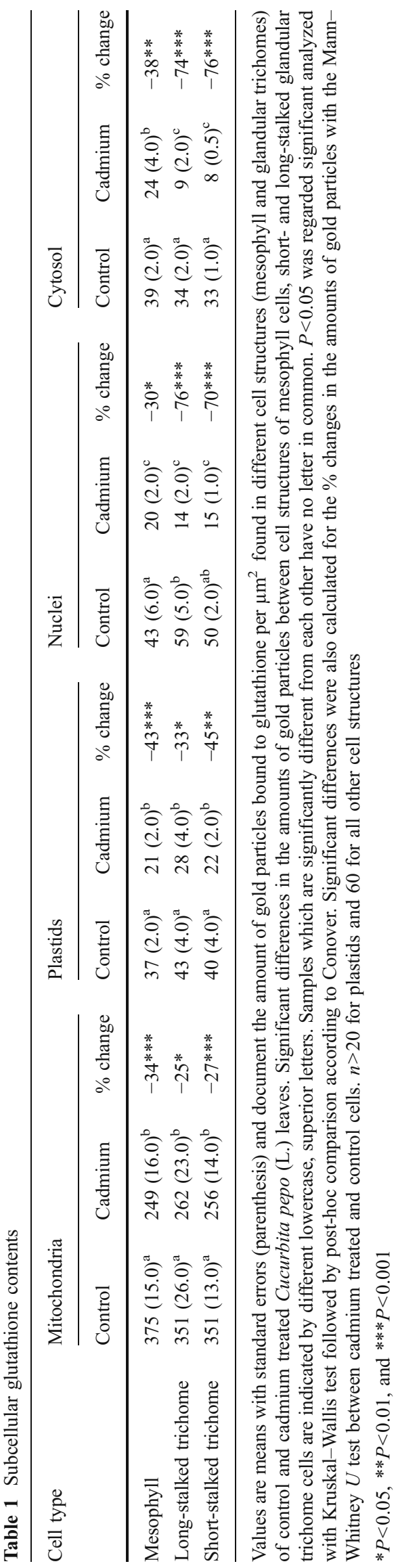


Table 2 Ratio of glutathione between organelles

\begin{tabular}{|c|c|c|c|c|c|c|c|c|}
\hline \multirow[t]{2}{*}{ Cell type } & \multicolumn{2}{|c|}{ Mitochondria } & \multicolumn{2}{|l|}{ Plastids } & \multicolumn{2}{|l|}{ Nuclei } & \multicolumn{2}{|l|}{ Cytosol } \\
\hline & Control & Cadmium & Control & Cadmium & Control & Cadmium & Control & Cadmium \\
\hline Mesophyll & 76.0 & 77.0 & 7.4 & 6.5 & 8.7 & 9.0 & 7.9 & 7.5 \\
\hline Long-stalked trichome & 72.0 & 83.5 & 8.8 & 9.2 & 12.2 & 4.5 & 7.0 & 2.8 \\
\hline Short-stalked trichome & 74.0 & 84.9 & 8.5 & 7.3 & 10.5 & 5.0 & 7.0 & 2.8 \\
\hline
\end{tabular}

Ratio (in \%) of the distribution of gold particles bound to glutathione between cell compartments of control and cadmium stressed mesophyll cells, long- and short-stalked glandular trichome cells of Cucurbita pepo (L.). Calculations were done with the data shown in Table 1

vulgaris, and C. pepo leaf cells which also showed highest levels of glutathione in mitochondria and lowest levels in plastids with intermediate labeling in nuclei and the cytosol (Zechmann et al. 2006, 2008, 2009). No or only very little glutathione was detected in vacuoles and in the apoplast before and after $\mathrm{Cd}$ exposure. These results indicate that free glutathione does not play an important role in the detoxification of $\mathrm{Cd}$ or $\mathrm{Cd}$-induced reactive oxygen species in the apoplast and that free glutathione does not get released in large amounts into the vacuoles after the transport of glutathione- $\mathrm{Cd}$ complexes into the vacuoles. The absence of immunogold-labeling in vacuoles also demonstrates that the present immunohistochemical approach of glutathione does not recognize glutathione bound to heavy metals in vacuoles where glutathione-Cd-complexes are sequestered after complexation in the cytosol.

After $\mathrm{Cd}$ exposure, no ultrastructural alterations were observed in leaf and glandular trichome cells and no visible signs of Cd-toxicity were observed on the leaves (data not shown). These data are similar to what was found in other glandular trichome cells that were treated with $50 \mu \mathrm{M}$ $\mathrm{CdCl}_{2}$ and also showed no ultrastructural alterations (Pietrini et al. 2003). However, glutathione contents were strongly affected by the treatment of $\mathrm{Cd}$. All organelles showed a strong decrease in glutathione contents after $48 \mathrm{~h}$ of $50 \mu \mathrm{M} \mathrm{CdCl}$-treatment of up to $43 \%$ in plastids of mesophyll cells and up to $76 \%$ in nuclei and the cytosol of long- and short-stalked glandular trichome cells. This decrease in glutathione contents is in line of recent reports that have also shown a decrease in glutathione contents after Cd treatment (Semane et al. 2007; Liu et al. 2007; Ammar et al. 2008; Dučić et al. 2008) and documents the importance of glutathione in the detoxification of $\mathrm{Cd}$. The decrease in glutathione contents after $\mathrm{Cd}$ treatment reflects the involvement of glutathione in $\mathrm{Cd}$ detoxificaton. Glutathione detoxifies $\mathrm{Cd}$ directly by complexation through the thiol group and subsequently by the transport into and sequestration in vacuoles. It also plays important roles as a Pc precursor, which is, besides glutathione and metallothioneins, an important component for $\mathrm{Cd}$ detoxification (Toppi and Gabbrielli 1999; Rauser 2001; DalCorso et al
2008). Therefore, it seems that the contents of free glutathione strongly decrease within leaf cells during $\mathrm{Cd}$ exposure as it is used for Pc synthesis and for the complexation and sequestration of $\mathrm{Cd}$ in vacuoles.

Nevertheless, a strong difference in the decline of glutathione in certain organelles was observed between mesophyll cells and glandular trichome cells. In mesophyll cells, glutathione was decreased between $30 \%$ and $43 \%$ depending on the organelle. In glandular trichome cells, a similar decrease was found in mitochondria and plastids. However glutathione contents in nuclei and the cytosol were decreased between $70 \%$ and $76 \%$ in glandular trichome cells. These results strongly indicate that glutathione in these two cell compartments plays a crucial role in the detoxification of $\mathrm{Cd}$ in glandular trichome cells. These results are also supported by observations that glandular trichomes can accumulate large amounts of $\mathrm{Cd}$ and might even be considered the major compartment of $\mathrm{Cd}$ accumulation in leaves (Ager et al. 2002, 2003; Isaure et al. 2006; Harada and Choi 2008). Especially the cytosol seems to be important for $\mathrm{Cd}$ detoxification in glandular trichomes as a decrease between $74 \%$ and $76 \%$ could be observed. Considering the high affinity of $\mathrm{Cd}$ to thiol components (Rauser 2001; DalCorso et al. 2008), this seems logical as the cytosol represents the first cell compartment that gets in contact with $\mathrm{Cd}$ after its uptake into the cell. Additionally, the cytosol is the major compartment for Pc synthesis and therefore a strong decrease of glutathione during $\mathrm{Cd}$ exposure in the cytosol as observed in the present study would be a logical consequence. However, it remains unclear why such a large decrease in glutathione contents could also be observed in nuclei but not in plastids and the mitochondria of glandular trichomes during $\mathrm{Cd}$ exposure. In general, the precise role of glutathione in nuclei of plant cells is unclear, even though it has been detected there with light microscopical techniques after monochlorobimane staining and with immunohistochemical methods in different plant species (Müller et al. 2005; Zechmann et al. 2006, 2009). It has been proposed for mammalian cells that glutathione in nuclei protects DNA from oxidative modifications, as the latter were negatively correlated with 
reduced nuclear glutathione content (Green et al. 2006). Nevertheless, the generation of large amounts of reactive oxygen species and also the accumulation of large amounts of $\mathrm{Cd}$ in nuclei seems to be unlikely as $\mathrm{Cd}$ accumulation are mainly restricted to the cytoplasm and in vacuoles (Van Belleghem et al. 2007). Therefore, the strong decrease of glutathione during $\mathrm{Cd}$ exposure in nuclei in glandular trichomes can only be explained by a Cd-induced relocalization of glutathione from nuclei into the cytosol where it plays important roles in the detoxification of $\mathrm{Cd}$ as described above. Support for this hypothesis comes from the large decrease in the ratio of glutathione between nuclei and the cytosol in comparison to all other investigated cell organelles in glandular trichome cells. Whereas the ratio of glutathione between cell organelles did not change in mesophyll cells after $\mathrm{Cd}$ exposure, a more than 50\% decrease was detected in nuclei and the cytosol of glandular trichome cells. These results indicate that these two compartments were especially affected by $\mathrm{Cd}$ treatment and that glutathione was withdrawn from the nuclei to the cytosol in order to assuage the higher demand of glutathione for $\mathrm{Cd}$ detoxification in the cytosol. Only a minor shift was found in plastids and mitochondria after $\mathrm{Cd}$ exposure when compared to the control. The increase in the ratio of glutathione in mitochondria of glandular trichomes in comparison to the other cell compartments that showed decreased glutathione contents also strengthens the previous made hypothesis that high and stable levels of glutathione in mitochondria are important for cell survival strategies especially during stress situations like the present Cd exposure (Zechmann et al. 2006, 2008).

Summing up, short time $50 \mu \mathrm{M} \mathrm{CdCl}_{2}$ exposure did not lead to ultrastructural changes in leaf and glandular trichome cells of Styrian oil pumpkin, but caused a significant decrease in subcellular glutathione levels. As the decrease was found to be strongest in the cytosol and nuclei of glandular trichome cells, it seems that these two cell compartments play a crucial role in the detoxification of $\mathrm{Cd}$ in glandular trichome cells. Additionally, it seems that a massive amount of glutathione is withdrawn from nuclei during $\mathrm{Cd}$ exposure in order to assuage the higher demand of glutathione in the cytosol for the detoxification of $\mathrm{Cd}$. The present results also indicate that low contents of glutathione may limit the operation of the glutathioneascorbate cycle in the detoxification of $\mathrm{Cd}$ in the long term, which could lead to oxidative stress, lipid peroxidation, and, eventually, to plant death.

Acknowledgments This work was supported by the Austria Sciences Fund (FWF, P18976, and P20619). We also wish to thank G. Graggaber for technical assistance during this work.

Conflict of interest The authors declare that they have no conflict of interest.
Open Access This article is distributed under the terms of the Creative Commons Attribution Noncommercial License which permits any noncommercial use, distribution, and reproduction in any medium, provided the original author(s) and source are credited.

\section{References}

Ager FJ, Ynsa MD, Domínguez-Solís JR, Gotor C, Respaldiza MA, Romero LC (2002) Cadmium localization and quantification in the plant Arabidopsis thaliana using micro-PIXE. Nucl Instrum Methods Phys Res B 189:494-498. doi:10.1016/S0168-583X (01)01130-2

Ager FJ, Ynsa MD, Domínguez-Solís JR, López-Martin MC, Gotor C, Romero LC (2003) Nuclear micro-probe analysis of Arabidopsis thaliana leaves. Nucl Instrum Methods Phys Res B 210:401406. doi:10.1016/S0168-583X(03)01046-2

Ammar WB, Mediouni C, Tray B, Ghorbel MH, Jemal F (2008) Glutathione and phytochelatin contents in tomato plants exposed to cadmium. Biol Plant 52:314-320. doi:10.1007/s10535-0080065-9

Bortz J, Lienert GA, Bohenke K (2000) Verteilungsfreie Methoden in der Biostatistik. Springer, Berlin

Choi YE, Harada E, Wada M, Tsuboi H, Morita Y, Kusano T, Sano H (2001) Detoxification of cadmium in tobacco plants: formation and active excretion of crystals containing cadmium and calcium through trichomes. Planta 213:45-50. doi:10.1007/s004250000 487

Cobbett CS, May MJ, Howden R, Rolls B (1998) The glutathionedeficient, cadmium-sensitive mutant, cad2-1, of Arabidopsis thaliana is deficient in c-glutamylcysteine synthetase. Plant $\mathrm{J}$ 16:73-78. doi:10.1046/j.1365-313x.1998.00262.x

DalCorso G, Farinati S, Maistri S, Furini A (2008) How plants cope with cadmium: staking all on metabolism and gene expression. J Integr Plant Biol 50:1268-1280. doi:10.1111/j.1744-7909.2008. 00737.x

Dučić T, Maksimović V, Radotić K (2008) Oxalate oxidase and nonenzymatic compounds of the antioxidative system in young Serbian spruce plants exposed to cadmium stress. Arch Biol Sci Belgrade 60:67-76. doi:10.2298/ABS0801067D

Ekmekci Y, Tanyolac D, Ayhana B (2008) Effects of cadmium on antioxidant enzyme and photosynthetic activities in leaves of two maize cultivars. J Plant Physiol 165:600-611. doi:10.1016/j. jplph.2007.01.017

Green RM, Graham M, O'Donovan MR, Chipman JK, Hodges NJ (2006) Subcellular compartmentalization of glutathione: Correlations with parameters of oxidative stress related to genotoxicity. Mutagenesis 21:383-390. doi:10.1093/mutage/gel043

Harada E, Choi YE (2008) Investigation of metal exudates from tobacco glandular trichomes under heavy metal stresses using a variable pressure scanning electron microscopy system. Plant Biotechnol 25:407-411

He JY, Ren YF, Zhu C, Yan YP, Jiang DA (2008) Effect of Cd on growth, photosynthetic gas exchange, and chlorophyll fluorescence of wild and $\mathrm{Cd}$-sensitive mutant rice. Photosynthetica 46:466-470. doi:10.1007/s11099-008-0080-2

Hegedüs A, Erdei S, Horváth G (2001) Comparative studies of $\mathrm{H}_{2} \mathrm{O}_{2}$ detoxifying enzymes in green and greening barley seedlings under cadmium stress. Plant Sci 160:1085-1093. doi:10.1016/ S0168-9452(01)00330-2

Howden R, Andersen CR, Goldsbrough PB, Cobbett CS (1995) A cadmium-sensitive, glutathione-deficient mutant of Arabidopsis thaliana. Plant Physiol 107:1067-1073. doi:10.1104/pp.107.4. 1067 
Isaure MP, Fayard B, Sarret G, Pairis S, Bourguignon J (2006) Localization and chemical forms of cadmium in plant samples by combining analytical electron microscopy and X-ray spectromicroscopy. Spectrochimica Acta Part B 61:1242-1252. doi:10. 1016/j.sab.2006.10.009

Kolb D, Müller M (2004) Light, conventional and environmental scanning electron microscopy of the trichomes of Cucurbita pepo subsp. pepo var. styriaca and histochemistry of glandular secretory products. Ann Bot (Lond) 94:515-526. doi:10.1093/aob/mch180

Liu Y, Wang X, Zeng G, Qu D, Gu J, Zhou M, Chai L (2007) Cadmium-induced oxidative stress and response of the ascorbate-glutathione cycle in Bechmeria nivea (L.) Gaud. Chemosphere 69:99-107. doi:10.1016/j.chemosphere.2007.04.040

Maksymiec W, Krupa Z (2006) The effects of short-term exposition to $\mathrm{Cd}$, excess $\mathrm{Cu}$ ions and jasmonate on oxidative stress appearing in Arabidopsis thaliana. Environ Exp Bot 57:187-194. doi:10.1016/j.envexpbot.2005.05.006

Mendoza-Cózatl D, Loza-Tavera H, Hernandez-Navarro A, MorenoSanchez R (2005) Sulfur assimilation and glutathione metabolism under cadmium stress in yeast, protists and plants. FEMS Microbiology Reviews 29:653-671

Mendoza-Cózatl DG, Butko E, Springer F, Torpey JW, Komives EA, Kehr J, Schroeder JI (2008) Identification of high levels of phytochelatins, glutathione and cadmium in the phloem sap of Brassica napus. A role for thiol-peptides in the long-distance transport of cadmium and the effect of cadmium on iron translocation. Plant J 54:249-259. doi:10.1111/j.1365-313X.2008. 03410.x

Müller M, Zellnig G, Urbanek A, Zechmann B (2005) Recent developments in methods intracellulary localizing glutathione within plant tissues and cells (a minivreview). Phyton (Horn) Austria 45:45-55

Nocito FF, Espen L, Crema B, Cocucci M, Sacchi GA (2008) Cadmium induces acidosis in maize root cells. New Phytol 179:700-711. doi:10.1111/j.1469-8137.2008.02509.x

Paradiso A, Berardino R, de Pinto MC, Toppi LS, Storelli MM, Tommasi F, de Gara L (2008) Increase in ascorbate-glutathione metabolism as local and precocious systemic responses induced by cadmium in durum wheat plants. Plant Cell Physiol 49:362374. doi: $10.1093 / \mathrm{pcp} / \mathrm{pcn} 013$

Pietrini F, Iannelli MA, Pasqualini S, Massacci A (2003) Interaction of cadmium with glutathione and photosynthesis in developing leaves and chloroplasts of Phragmites australis (Cav.) Trin. Ex Steudel.

Rauser WE (2001) The role of glutathione in plant reaction and adaptation to excess metals. In: Grill D, Tausz M, De Kok LJ (eds) Significance of glutathione to plant adaptation to the environment. Kluwer, Dordrecht, pp 123-154
Romero-Puertas MC, Palma JM, Gomez LA, del Rio LA, Sandalio LM (2002) Cadmium causes oxidative modification of proteins in plants. Plant Cell Environ 25:677-686. doi:10.1046/j.13653040.2002.00850.x

Schützendübel A, Schwanz P, Teichmann T, Gross K, LangenfeldHeyser R, Godbold DL, Polle A (2001) Cadmium-induced changes in antioxidative systems, hydrogen peroxide content, and differentiation in Scots pine roots. Plant Physiol 75:887-898. doi:10.1104/pp.010318

Semane B, Cuypers A, Smeets K, Van Belleghem F, Horemans N, Schat H, Vangronsveld J (2007) Cadmium responses in Arabidopsis thaliana: glutathione metabolism and antioxidative defence system. Physiol Plant 129:519-528. doi:10.1111/j.13993054.2006.00822.x

Singh S, Eapen S, D’Souza SF (2006) Cadmium accumulation and its influence on lipid peroxidation and antioxidative system in an aquatic plant, Bacopa monnieri L. Chemosphere 61:233-246. doi:10.1016/j.chemosphere.2005.05.017

Toppi LS, Gabbrielli R (1999) Response to cadmium in higher plants. Environ Exp Bot 41:105-130. doi:10.1016/S0098-8472(98) 00058-6

Van Belleghem F, Cuypers A, Semane B, Smeets K, Vangronsveld J, d'Haen J, Valcke R (2007) Subcellular localization of cadmium in roots and leaves of Arabidopsis thaliana. New Phytol 173:495-508. doi:10.1111/j.1469-8137.2006.01940.x

Xu P, Zou J, Meng Q, Zou J, Jiang W, Liu D (2008) Effects of Cd2+ on seedling growth of garlic (Allium sativum L.) and selected physiological and biochemical characters. Bioresour Technol 99:6372-6378. doi:10.1016/j.biortech.2007.11.073

Zawoznik MS, Groppa MD, Tomaro ML, Benavides MP (2007) Endogenous salicylic acid potentiates cadmium-induced oxidative stress in Arabidopsis thaliana. Plant Sci 173:190-197. doi:10.1016/j.plantsci.2007.05.004

Zechmann B, Müller M, Zellnig G (2006) Intracellular adaptations of glutathione content in Cucurbita pepo (L.) induced by reduced glutathione and buthionine sulfoximine treatment. Protoplasma 227:197-209. doi:10.1007/s00709-005-0129-z

Zechmann B, Mauch F, Sticher L, Müller M (2008) Subcellular immunocytochemical analysis detects the highest concentrations of glutathione in mitochondria and not in plastids. J Exp Bot 59:4017-4027. doi:10.1093/jxb/ern243

Zechmann B, Mauch F, Zelena E, Müller M (2009) Subcellular distribution of glutathione in plants. In: Sirko A, de Kok LJ, Haneklaus S, Hawkesford MJ, Rennenberg H, Saito K, Schnug E, Stulen I (eds) Sulfur metabolism in plants. Regulatory aspects, significance of sulfur in the food chain, agriculture and the environment. Margraf Publishers, Germany, pp. 225-229. 